\title{
Exercise and inflammatory bowel disease
}

\author{
Neeraj Narula BSc, Richard N Fedorak MD
}

N Narula, RN Fedorak. Exercise and inflammatory bowel disease. Can J Gastroenterol 2008;22(5):497-504.

Crohn's disease and ulcerative colitis are both idiopathic inflammatory bowel diseases (IBDs) that affect $0.5 \%$ of Canadians. As yet, there is no known cure for either disease, and symptoms are treated with an array of medicines. The objective of the present review was to present the role of exercise and its impact on all facets of IBD. Exercise has been speculated to be protective against the onset of IBD, but the literature is inconsistent and weak. Preliminary studies reveal that exercise training may be beneficial to reduce stress and symptoms of IBD. Current research also recommends exercise to help counteract some IBD-specific complications by improving bone mineral density, immunological response, psychological health, weight loss and stress management ability. However, the literature advises that some patients with IBD may have limitations to the amount and intensity of exercise that they can perform. In summary, exercise may be beneficial to IBD patients, but further research is required to make a convincing conclusion regarding its role in the management of IBD and to help establish exercise regimens that can account for each IBD patient's unique presentation.

\section{Exercice et maladie inflammatoire de l'intestin}

La maladie de Crohn et la colite ulcéreuse sont deux maladies inflammatoires de l'intestin (MII) idiopathiques qui affectent 0,5\% des Canadiens. On ne dispose encore d'aucun remède pour guérir ces maladies, et leurs symptômes sont traités au moyen de divers médicaments. L'objectif de la présente synthèse était d'étudier le rôle de l'exercice et son impact sur toutes les facettes des MII. L'exercice conférerait une protection contre le déclenchement des MII, mais la littérature à cet égard laisse à désirer sur le plan de la qualité et de la cohésion des preuves. Des études préliminaires révèlent que l'entraînement physique peut être bienfaisant en réduisant le stress et en atténuant les symptômes de MII. La recherche actuelle recommande aussi l'exercice pour lutter contre certaines complications spécifiques des MII en améliorant la densité minérale osseuse, les réactions immunologiques, la santé psychologique, la perte de poids et la réduction du stress. Par contre, selon la littérature, certains patients atteints de MII doivent limiter la durée et l'intensité de leur entraînement. En résumé, l'exercice peut être bienfaisant pour les patients atteints de MII, mais il faudra approfondir la recherche pour en arriver à une conclusion probante au sujet de son rôle dans la prise en charge de la MII et établir des programmes d'entraînement établis au cas par cas.

Key Words: Bone mineral density; Crohn's disease; Exercise; Inflammatory bowel diseases; Pouchitis; Ulcerative colitis

C rohn's disease $(\mathrm{CD})$ and ulcerative colitis (UC) are both inflammatory bowel diseases (IBDs) that affect approximately $0.5 \%$ of Canadians (1). Disease onset can occur at any age and typically peaks at 20 to 29 years of age (1). The generally accepted theory is that a combination of environmental agent(s) and a dysfunctional mucosal immune system in genetically susceptible individuals leads to the development of either $\mathrm{CD}$ or $\mathrm{UC}(2,3)$. CD can involve any portion of the gastrointestinal tract, while UC is restricted to the rectum through to the large intestinal tract. The chronic diseases are characterized by a cyclical nature, alternating between active and quiescent states that negatively affect the patient's quality of life. For CD patients, active periods may also be accompanied by the formation of sinus tracts and fistulas, strictures or granulomas. As yet, there is no known cure for either disease, and symptoms are treated with an array of medications (ie, 5-aminosalicylic acid compounds, corticosteroids, cyclosporin, tacrolimus or biological agents such as infliximab), each of which is associated with undesirable side effects $(2,4)$. In severe instances, such as toxic megacolon or fistula drainage and repair, surgical intervention is necessary.
Advances in surgical techniques have led to the routine creation of an internal storage reservoir (ileal J-pouch anal anastomosis) versus the traditional proctocolectomy with external ileostomy bag, because it is less obtrusive and enhances the patient's quality of life.

In 1998, guidelines (5) designed specifically for IBD patients promoted the benefits of exercise for overall health, minimizing or reversing muscle weakness, and improving bone mineral density. The guidelines indicated aerobic activity for $20 \mathrm{~min}$ to $60 \mathrm{~min}$ two to five days every week, complemented by resistance training at least twice per week. This is the first and only comprehensive exercise worksheet intended for IBD patients; however, these recommendations have not been integrated into the accepted literature - the paper has only been cited one other time since its publication (according to SCOPUS). Before 1999, there were no research studies that investigated the role of exercise in IBD patients. Thus, in 1998, the guidelines were based on the benefits of exercise for healthy individuals, and meaningful information was extrapolated from previously collected information regarding the benefits of exercise in IBD patients and its benefit in other diseases.

Division of Gastroenterology, University of Alberta, Edmonton, Alberta

Correspondence: Dr Richard N Fedorak, University of Alberta, Division of Gastroenterology, Zeidler Ledcor Centre, Edmonton, Alberta

T6G 2X8. Telephone 780-492-6941, fax 780-492-8121, e-mail richard.fedorak@ualberta.ca

Received for publication December 10, 2008. Accepted February 24, 2008. 
At present, it has been well established that exercise reduces the RR for colon cancer by as much as $50 \%$ and decreases the time required for gastric emptying (6). Exercise has also been associated with improved psychological wellbeing, better health and improved quality of life (7-11). However, there are drawbacks to the gastrointestinal benefits of exercise. During prolonged, intensive training or extreme exercise such as triathlons, approximately $30 \%$ to $81 \%$ of individuals experience a range of gastrointestinal complaints including cramps, bloating, diarrhea ('runner's trots'), heartburn, nausea and fecal incontinence $(6,12)$. These temporary issues are attributed to an $80 \%$ reduction in blood flow to the gut, compounded further by mechanical trauma sustained by repeated bouncing (12). Studies indicate that $8 \%$ to $85 \%$ of marathoners experience transient, occult bleeding, and an unreported number suffer from the more severe form, 'runner's ischemic colitis', involving bloody diarrhea, fatigue and fever (12). The athlete's increased tolerance to physical pain means that many do not seek medical attention for these temporary issues but, rather, accept them as necessary rigors associated with the pursuit of their sport.

To date, the role of exercise in the etiology of IBD has not been thoroughly investigated. Nevertheless, the scientific literature is replete with statements that IBD patients should exercise but should first inform their clinician. This pervasive attitude is typically supported by one or two reasons, when, in fact, there is a multiplicity of reasons for and against exercise that are unique to each IBD patient. Thus, the objective of the present review is to present the role of exercise and its relationship to all facets of IBD for the benefit of clinicians and their patients.

\section{SYSTEMATIC LITERATURE SEARCH}

A systematic search was conducted to retrieve high quality, peer-reviewed studies that investigated the association between exercise and any facet of IBD. The PubMed, MEDLINE, EMBASE and BIOSIS Previews databases were searched with text ('exercise', 'physical activity', 'colitis', 'Crohn' and 'inflammatory bowel disease') and MeSH terms ('Crohn's disease', 'ulcerative colitis', 'inflammatory bowel diseases', 'movement' and 'exercise'). Results were limited to those written in English. Similar searches were conducted to identify relevant abstracts presented at the 2006 and 2007 Digestive Disease Week meetings.

\section{EXERCISE AND THE ONSET OF IBD}

Several studies have examined the effect of lifestyle and behaviours as putative causal agents for the onset of IBD (Table 1). In 1990, Sonnenberg (13) conducted a retrospective study in which the preillness occupations of 12,014 German IBD patients were examined. The author concluded that outdoor occupations involving exercise were protective against the onset of IBD. In 1993, a small $(\mathrm{n}=725)$ case-control Swedish study (14) found that daily and weekly exercise five years previously reduced the risk for CD (RR 0.5, 95\% CI 0.3 to 0.9 , and RR $0.6,95 \%$ CI 0.4 to 0.9 , respectively) compared with randomly selected, healthy controls. However, the significance of this association did not hold for UC (RR 0.9, $95 \%$ CI 0.5 to 1.4 , for both daily and weekly exercise). A prospective Danish study (15) followed two cohorts, each comprised of more than 2.3 million individuals, for five or 10 years. Only a small, inconsistent association was found between sedentary occupations and the onset of IBD in women. In 1998, an Israeli study (16) determined that IBD patients $(n=88)$ had lower levels of physical activity during their preillness period than clinic controls $(n=68 ; P<0.001)$.

Although these four epidemiological studies found an association between sedentary occupations in the preillness period and the onset of IBD, the results are inconsistent and weak. The considerable range of confounding factors inherent in studies such as these further dilutes the significance of the findings. As a whole, these studies did not take into account the possibility that disease onset may be a gradual process longer than 10 years, during which individuals are forced to seek work environments to accommodate their transient physical discomforts. Similarly inconclusive was an American study (17) in which vital statistics for IBD mortalities were reviewed for occupational and industrial distributions. It remained unclear whether the individuals selected the sedentary occupations or were limited to these options by their physical needs. A metaanalysis of available information concluded that there was insufficient information to identify occupations that affect the risk of IBD onset (18).

In an effort to reduce the number of confounders such as genetics, and intrauterine and childhood environments, Halfvarson et al (19) conducted a twin study in which a cotwin had been diagnosed with IBD. Although retrospective in nature, with a median disease duration of 17 years, results were subject to recall bias. Nevertheless, there were no significant differences found between the twins in physical exercise before the diagnosis of IBD in a co-twin.

The results of these studies indicate that the degree of exercise obtained through occupation neither protects nor initiates the onset of IBD. This is in keeping with the current tenet regarding the etiology of IBD, which involves an individual's genetic composition, their immune system and environmental causal agents such as micro-organisms $(2,3)$. Indeed, there are both professional and amateur athletes who have been diagnosed with IBD at various time points in their careers, suggesting that exercise in the preillness period is not a protective factor for IBD onset (20-23).

\section{EXERCISE AND QUIESCENT DISEASE}

Of the five studies (24-28) that have examined the effect of exercise on IBD (CD, $\mathrm{n}=4 ; \mathrm{UC}, \mathrm{n}=1)$, each involved subjects with either quiescent disease or mild activity (Table 2). Overall, the studies assessed physiological and psychological variables before and after exercise interventions such as walking, stationary cycling or yoga. D'Inca et al (28) found that a single $60 \mathrm{~min}$ cycling session did not alter intestinal permeability or lipoperoxidation levels in IBD patients or in healthy subjects. No change in IBD disease status was observed immediately following the exercise session or six months later. Loudon et al (26) found that pre- and poststudy measures of quality of life and stress levels were significantly improved in their case series in which patients underwent a three-month walking regimen. Although not statistically significant, the trend indicated that the subjects' disease status also improved in association with exercise. Not surprisingly, the previously sedentary subjects experienced significant improvements in their aerobic capacity and body mass index (BMI). The secondary outcome of a 10day, yoga lifestyle intervention study (25) for anxiety was that none of the 175 cases experienced exacerbation of their medical conditions, including the 18 subjects with gastrointestinal conditions (including CD). Most recently, Ng et al (27) found that 
TABLE 1

Overview of observational studies examining the impact of exercise in the preillness period on inflammatory bowel disease (IBD)

\begin{tabular}{|c|c|c|c|c|c|}
\hline \multirow[b]{2}{*}{ Reference, year } & \multirow[b]{2}{*}{ Country } & \multirow[b]{2}{*}{ Study description } & \multicolumn{2}{|c|}{ Cohort size, n } & \multirow[b]{2}{*}{ Results } \\
\hline & & & CD & UC & \\
\hline $\begin{array}{l}\text { Sonnenberg (13), } \\
1990\end{array}$ & Germany & $\begin{array}{l}\text { Retrospectively reviewed Social } \\
\text { Security statistics of people } \\
\text { granted rehabilitation due to } \\
\text { IBD between } 1982 \text { and } 1988\end{array}$ & 12,014 & 0 & $\begin{array}{l}\text { Occupations in the preillness period that were either } \\
\text { sedentary in air-conditioned areas or that had } \\
\text { irregular hours were significantly associated with } \\
\text { IBD; identified } 15 \text { occupations having a } \\
\text { significant OR for IBD onset; highlighted } \\
\text { involvement of occupation with IBD onset }\end{array}$ \\
\hline $\begin{array}{l}\text { Persson et al (14), } \\
1993\end{array}$ & Sweden & $\begin{array}{l}\text { Postal questionnaire } \\
\text { Controls: healthy individuals } \\
(n=305)\end{array}$ & 152 & 145 & $\begin{array}{l}\text { CD onset inversely related to weekly and daily } \\
\text { exercise five years before disease onset (RR 0.6, } \\
95 \% \mathrm{Cl} 0.4-0.9 \text {, and RR } 0.5,95 \% \mathrm{Cl} 0.3-0.9 \\
\text { respectively); no association with UC }\end{array}$ \\
\hline $\begin{array}{l}\text { Boggild et al (15), } \\
1996\end{array}$ & Denmark & $\begin{array}{l}\text { Population followed from } 1981 \\
\text { to } 1990 \text { (cohort 1: five years; } \\
\text { cohort 2: } 10 \text { years); recorded } \\
\text { hospitalization rates for IBD; } \\
\text { combined results for patients } \\
\text { with either CD or UC }\end{array}$ & $\begin{array}{l}\text { Cohort 1: } \\
\mathrm{n}>2.3 \mathrm{M} \\
\text { Cohort 2: } \\
\mathrm{n}>2.4 \mathrm{M}\end{array}$ & & $\begin{array}{l}\text { Found } 13 \text { occupations with a significant OR for IBD, } \\
\text { but of these, } 11 \text { were different from those identified } \\
\text { by Sonnenberg (13); concluded that sedentary } \\
\text { office work may contribute to IBD onset, but no } \\
\text { other consistent pattern was identified }\end{array}$ \\
\hline Klein et al (16), 1998 & Israel & $\begin{array}{l}\text { Preillness lifestyle patterns } \\
\text { compared among } 88 \text { recently } \\
\text { diagnosed IBD patients and } \\
76 \text { population and } 68 \text { clinic controls }\end{array}$ & 33 & 55 & $\begin{array}{l}\text { IBD patients had lower levels of physical activity } \\
\text { versus clinic controls }(\mathrm{P}<0.001) \text {; more population } \\
\text { controls participated in moderate activity in the } \\
\text { corresponding period }(\mathrm{P}<0.05)\end{array}$ \\
\hline $\begin{array}{l}\text { Cucino et al (17) } \\
2001\end{array}$ & United States & $\begin{array}{l}\text { Examined the occupations of } \\
\text { individuals with all IBD mortalities } \\
\text { from } 1991 \text { to } 1996\end{array}$ & 2399 & 2419 & $\begin{array}{l}\text { IBD mortalities were low in manual occupations } \\
\text { and farming, and relatively high in indoor, } \\
\text { sedentary occupations; however, these were } \\
\text { occupations held at the time of death and may have } \\
\text { been chosen in response to symptoms of IBD }\end{array}$ \\
\hline $\begin{array}{l}\text { Halfvarson et al (19), } \\
2006\end{array}$ & $\begin{array}{l}\text { Sweden and } \\
\text { Denmark }\end{array}$ & $\begin{array}{l}\text { IBD discordant twin study using } \\
\text { a postal questionnaire } \\
\text { regarding preillness events }\end{array}$ & $\begin{array}{l}102 \text { pairs } \\
\text { of twins }\end{array}$ & $\begin{array}{r}125 \text { pairs } \\
\text { of twins }\end{array}$ & $\begin{array}{l}\text { No significant difference found in exercise } \\
\text { levels between twin pairs }\end{array}$ \\
\hline
\end{tabular}

CD Crohn's disease; M Million; UC Ulcerative colitis

a low-intensity walking intervention improved both the physiological and psychological health of patients with CD. One study (24) dealing with UC similarly concluded that the intervention cohort had a significant improvement in their quality of life and that exercise did not lead to remission relapse.

These five interventional studies had a number of limitations, such as the small cohort sizes (range $n=6$ to $n=30$ ), short duration of exercise intervention (range $1 \mathrm{~h}$ to three months), absence of endoscopies to directly visualize the effect of exercise on the intestinal tract and the exclusion of pediatric IBD patients. Additionally, only one study (24) examined the effect of exercise on UC patients. In spite of these limiting features, there is considerable uniformity in the findings of these studies exercise did not lead to relapse or exacerbate disease activity. This corroborating evidence adds strength to the overall value of the findings. Thus, it appears prudent to acknowledge that low- to moderate-intensity exercise is well tolerated by IBD patients who are in remission or have only mild disease activity. Evidence in support of this is provided by a larger $(n=200)$ case-control study (29) in which the daily physical activity (combined work, recreational and home activity) and physical exercise levels were measured prospectively for $\mathrm{CD}$ patients in remission and for healthy subjects. The authors found that the daily physical activity levels did not differ significantly between the case patients and control patients $(\mathrm{P}=0.115)$. Nevertheless, CD patients performed significantly less frequent and less intense physical exercise than their healthy counterparts $(\mathrm{P}<0.002)$. The authors concluded that the sedentary lifestyle of $C D$ patients in remission may be putatively targeted as a health promotion strategy but cautioned that further research is merited.

\section{EXERCISE LIMITATIONS OF IBD PATIENTS}

For IBD patients experiencing moderate to severe disease activity, there are several practical reasons to discourage exercise, such as physical restrictions, inconvenience and discomfort. Patients who are in remission or experiencing mild disease activity may safely engage in low- to moderate-intensity exercise without directly compromising their disease status. However, there are several exceptions that need to be considered.

\section{Surgical resection of the intestinal tract}

In 1995, Brevinge et al (30) investigated the physical ability of three cohorts of $\mathrm{CD}$ patients who had undergone minimal (less than $10 \mathrm{~cm}$ of the small bowel), moderate (15\% to $30 \%$ of the small bowel) and extensive (more than 50\% of the small bowel) surgical resection to abrogate their symptoms. At the time of the study, all patients were in remission. The matched 
TABLE 2

Overview of interventional studies examining the impact of exercise on inflammatory bowel disease (IBD)

\begin{tabular}{|c|c|c|c|c|}
\hline Reference, year & Methods & Intervention (duration) & Outcome(s) measured & Results \\
\hline \multicolumn{5}{|c|}{ Crohn's disease (CD) } \\
\hline $\begin{array}{l}\text { D'Inca et al (28), } \\
1999\end{array}$ & $\begin{array}{l}\text { Cases: } 6 \text { men, } \\
\text { CD in remission } \\
\text { Controls: } 6 \text { healthy } \\
\text { men }\end{array}$ & $\begin{array}{l}\text { Moderate cycling exercise at a } \\
\text { maximum of } 60 \% \text { oxygen } \\
\text { consumption ( } 60 \mathrm{~min})\end{array}$ & $\begin{array}{l}\text { Intestinal permeability } \\
\text { and lipoperoxidation } \\
\text { Disease activity } 6 \text { months } \\
\text { after intervention }\end{array}$ & $\begin{array}{l}\text { No significant effect on the } \mathrm{Gl} \\
\text { parameters examined; no change } \\
\text { in disease activity immediately or after } \\
6 \text { months }\end{array}$ \\
\hline $\begin{array}{l}\text { Loudon et al (26), } \\
1999\end{array}$ & $\begin{array}{l}\text { Cohort of } 12 \mathrm{CD} \\
\text { patients, either in } \\
\text { remission or with } \\
\text { mild activity }\end{array}$ & $\begin{array}{l}\text { Low-intensity walking program: } \\
3 \times 32.6 \text { min (mean) each week } \\
(3 \text { months })\end{array}$ & $\begin{array}{l}\mathrm{BMI} \\
\mathrm{HBI} \\
\mathrm{IBDQ} \\
\text { IBDSI }\end{array}$ & $\begin{array}{l}\text { Reductions in all IBD pre- and poststudy } \\
\text { measures }(P<0.05) \text {; } B M I \text { and aerobic } \\
\text { capacity also improved; no change in } \\
\text { disease activity }\end{array}$ \\
\hline $\begin{array}{l}\text { Gupta et al (25), } \\
2006\end{array}$ & $\begin{array}{l}\text { Cases: } 175 \text { patients } \\
\text { (18 had GI issues } \\
\text { including CD) } \\
\text { Controls: } 50 \text { patients } \\
\text { All had anxieties and } \\
\text { medical conditions }\end{array}$ & $\begin{array}{l}\text { Yoga, meditation, stress } \\
\text { management, nutrition, group } \\
\text { support ( } 10 \text { days) }\end{array}$ & STAI & $\begin{array}{l}\text { Significantly decreased pre- and } \\
\text { poststudy STAI scores in the case } \\
\text { group; for subjects with GI issues, } \\
\text { the decrease was not significant; } \\
\text { no change in disease activity }\end{array}$ \\
\hline \multicolumn{5}{|c|}{ Ulcerative colitis (UC) } \\
\hline $\begin{array}{l}\text { Elsenbruch (24), } \\
2005\end{array}$ & $\begin{array}{l}\text { Cases: } 30 \text { UC patients } \\
\text { Controls: } 30 \text { UC patients } \\
\text { All were in remission } \\
\text { or had mild disease } \\
\text { activity }\end{array}$ & $\begin{array}{l}60 \mathrm{~h} \text { training program: stress } \\
\text { management training, moderate } \\
\text { exercise, Mediterranean diet, } \\
\text { behavioural techniques and } \\
\text { self-care strategies (10 weeks; } \\
6 \mathrm{~h} / \text { week) }\end{array}$ & IBDQ & $\begin{array}{l}\text { Intervention group showed significantly } \\
\text { greater improvement on the IBDQ scale; } \\
\text { no change in disease activity }\end{array}$ \\
\hline
\end{tabular}

BMI Body mass index; GI Gastrointestinal; HBI Harvey and Bradshaw Simple Index; IBDQ Inflammatory Bowel Disease Quality of Life Score; IBDSI Inflammatory Bowel Disease Stress Index; IPAQ International Physical Activity Long Questionnaire; STAI State Trait Anxiety Inventory

control group was comprised of healthy hospital staff members with sedentary lifestyles. Maximal exercise load was evaluated using cycle ergometry and took into account body composition and metabolic variables. Compared with the control group, the maximal exercise load of the three case groups decreased according to the extent of the resection ( $9 \%$ to $40 \%$ reduction). The actual working capacity for both the moderate and extensive resectioned groups was lower than calculated, even after accounting for reduced muscle mass. The urinary metabolite profiles indicated malnutrition attributed to the reduced absorptive area of their remaining intestinal tract. The authors concluded that IBD patients who undergo moderate to extensive surgical resection are incapable of activity requiring high-energy consumption $(500 \mathrm{~W}$ to $700 \mathrm{~W})$. Furthermore, each case group overestimated their actual working capacity as measured by the ergometry test. The potential to dangerously overexert oneself is a real hazard, yet few appear cognizant of this fact. The authors made no comments regarding the appropriateness of a suitable exercise regimen to improve the general health of IBD patients who have undergone surgical resection.

\section{Muscle function}

Wiroth et al (31) compared the muscular function of $41 \mathrm{CD}$ patients in remission against 25 age-matched, healthy controls. Both muscle strength and endurance were reduced in the $\mathrm{CD}$ cohort, which were most profound in the lower limbs $(\mathrm{P}<0.001)$. A similar phenomenon has been noted in the elderly, whereby there is a gradual decrease in the use of leg muscles, with little change in upper body activity (32). Surprisingly, muscle performance was independent of prior disease duration or severity, current inflammation, cumulative dose of glucocorticoids and global physical activity. Specifically, work and sport activity indexes were significantly reduced in the $\mathrm{CD}$ cohort compared with the controls $(\mathrm{P}<0.05)$. It is possible that these two factors may contribute largely to the reduced muscular performance in the CD cohort. Yet, until the etiology of muscle deterioration in $\mathrm{CD}$ is understood, it is unknown whether the disease itself or the treatments are the causal agents. Although no studies involving UC patients have been published, it is likely that these patients experience decreased muscle performance because they have similar symptoms and treatments. The authors suggest that strength training during periods of remission may help to minimize or reverse decreased muscular performance. However, it is important to alert patients to their reduced physical abilities, to minimize overexertion or subsequent depression.

\section{BENEFITS OF EXERCISE FOR IBD PATIENTS}

For most, regular exercise leads to good health. In particular, IBD patients may experience additional benefits such as minimizing extraintestinal manifestations of their disease (Table 2). 


\section{Ankylosing spondylitis}

While $12 \%$ to $23 \%$ of IBD patients are expected to have peripheral arthritis of varying forms, ankylosing spondylitis has been specifically associated with IBD (33). According to the literature, the percentage of IBD patients who develop ankylosing spondylitis falls within a combined range of $0.9 \%$ to $8 \%$ (33). As well, $4 \%$ to $18 \%$ of IBD patients have been radiographically diagnosed with asymptomatic sacroiliitis, but it is unknown how many of these progress to ankylosing spondylitis. Treatment modalities for ankylosing spondylitis involve a combination of exercise and drug therapy $(34,35)$. Results of several randomized, controlled trials $(36-38)$ have provided corroborating evidence indicating the effectiveness of exercise therapy for improving flexibility (especially in the spinal column) and strength, and for pain reduction in the joints.

\section{Osteoporosis in $\mathrm{CD}$ patients}

Approximately 50\% of CD patients develop osteopenia and a further $13 \%$ subsequently progress to osteoporosis (39). These high rates merit bone density scans (ie, dual energy $\mathrm{x}$-ray absorptiometry scanning) in diseased individuals who are at risk for osteoporosis, such as those having a low body weight or suffering from malnutirition (39-42). Glucocorticoid treatment was believed in the past to be a major contributor to bone mineral loss. However, numerous studies (43-47) have indicated that it is a significant but minor contributor compared with the increased rates of bone resorption found in CD patients. Furthermore, bone turnover rates are substantially reduced and are hypothesized to be partially responsible for pediatric patients not achieving their full skeletal growth potential $(44,45)$. Bone mineral loss leads to fractures, complications and skeletal morbidity, all of which can be avoided through early supplementation with vitamin $\mathrm{D}$ and calcium (40). A limited number of pharmacological therapies (ie, bisphosphonates, bone resorption inhibitors and bone growth promoters) have proven effective for individuals presenting with severe bone loss, but these are associated with undesirable side effects (48-50). In healthy individuals, exercise alone has been associated with increased bone mineral density $(41,51)$. Physical exercise also increases bone mineral density in postmenopausal women and elderly people, and is a safe, inexpensive, accessible option for premenopausal women to prevent osteoporosis later in life $(40,41,52)$.

To date, one randomized, controlled trial (53) has examined the effect of a low-impact exercise program on bone mineral density in $\mathrm{CD}$ patients. At the conclusion of the 12 -month study, the exercise cohort $(n=53)$ had significantly $(\mathrm{P}>0.05)$ increased bone mineral density measurements in the hip and spine compared with the control group $(n=54)$. The authors noted that only $52 \%$ of the exercise cohort completed the twice weekly exercise regimen over the course of one year. The lower than anticipated compliance was attributed to the remission-relapse cyclical nature of CD. A followup to this study was conducted eight years later, during which time subjects were free to select their level of activity (54). No significant differences in bone mineral density were found between those originally randomly assigned to the exercise $(n=26)$ and control $(n=29)$ cohorts, indicating that the effects of short-term exercise are not long lasting. However, significant differences were found in both the spine and hip when patients with higher levels of current activity were compared with those who were the least active $(\mathrm{P}=0.015$ and
$\mathrm{P}=0.027$, respectively). A recent observational study (54) found a distinct association of activity and muscle mass with bone strength and bone mass in CD patients. As a whole, findings from these three papers indicated that $\mathrm{CD}$ patients should engage in regular exercise to achieve and maintain maximal bone density, which is similar to recommendations for those in the general population who are at increased risk for osteoporosis $(41,55)$.

\section{Stress management}

For the general population, it is a well-established dogma that regular exercise improves psychological health by reducing depression and anxiety while improving one's self-image. This is especially applicable in IBD patients who typically report higher levels of daily stress and a lower quality of life than the general population (56-58). Although it is unclear whether stress affects the course of bowel disease, reducing a patient's daily stress level may increase their overall quality of life $(8,59)$.

\section{Immune response}

Several studies (60-62) have shown an association between low to moderate exercise and an improvement in the immune system, while intensive or prolonged bouts are detrimental. IBD is a chronic condition in which the immune system is compromised. Treatment may involve immunosuppressive drug therapy. As such, any therapy, especially of a nonpharmacological origin, that can boost the immune system has beneficial value.

\section{BMI}

The IBD patient is typically characterized as underweight and malnourished. However, the recent population trend to being overweight is also mirrored in newly diagnosed pediatric IBD patients. A recent American study (63) reported that $10 \%$ of CD and $20 \%$ to $30 \%$ of UC patients had BMI values consistent with being overweight or at risk for being overweight. Obesity and its effect on the course of IBD have been cursorily examined thus far (Table 3). The first study (64), published in 2002, found that obese (BMI more than $30 \mathrm{~kg} / \mathrm{m}^{2}$ ) CD patients developed anoperineal complications within a shorter time frame ( $P>0.03$ ), had more instances of active disease (OR 1.50, 95\% CI 1.07 to 2.11) and required more hospitalizations than CD patients with a normal BMI. A retrospective study (65) found that CD patients with a BMI of more than $25 \mathrm{~kg} / \mathrm{m}^{2}$ were significantly older at diagnosis $(\mathrm{P}=0.0001)$, and a trend indicated that they had a shorter median time to their first surgical procedure (72 versus 24 months) than their lighter counterparts (BMI less than $18.5 \mathrm{~kg} / \mathrm{m}^{2}$ ). A retrospective study (66) compared the outcomes of restorative proctocolectomy between 31 obese (BMI $30 \mathrm{~kg} / \mathrm{m}^{2}$ or more) and 31 nonobese UC patients. The obese cohort had higher rates of pelvic sepsis ( $16 \%$ versus $0 \%$, respectively; $\mathrm{P}<0.05$ ) and perioperative morbidity (32\% versus $9.6 \%$, respectively; $\mathrm{P}=0.058)$, supporting the belief that restorative proctocolectomy is contraindicated for obese patients. A 2006 case study (67) reported that a bariatric UC patient who lost $86.8 \%$ of his weight due to a gastric bypass experienced significant and sustained symptomatic improvement. A common treatment to induce remission in IBD patients is glucocorticoid therapy, which can cause weight gain, resulting in additional problems for patients with higher BMI values (29). 
TABLE 3

Overview of studies examining the impact of obesity on the clinical course of inflammatory bowel disease

\begin{tabular}{|c|c|c|c|c|}
\hline Reference, year & Descriptions of study groups & Study groups & Assessments & Results \\
\hline \multicolumn{5}{|c|}{ Crohn's disease (CD) } \\
\hline $\begin{array}{l}\text { Blain et al (64), } \\
2002\end{array}$ & $\begin{array}{l}\text { Cases: Obese (BMl>25 at disease } \\
\text { onset and }>30 \text { after diagnosis) } \\
\text { Controls: Normal BMl at all disease } \\
\text { stages }\end{array}$ & $\begin{array}{l}\text { Cases }(n=62) \\
\text { Controls }(n=124)\end{array}$ & $\begin{array}{l}\text { Sex, disease location, } \\
\text { behaviour, severity, } \\
\text { complications and age }\end{array}$ & $\begin{array}{l}\text { Cases had a shorter time to develop } \\
\text { anoperineal penetrating complications } \\
(\mathrm{P}>0.03) \text {, and were more prone to active } \\
\text { disease (OR } 1.50,95 \% \mathrm{Cl} 1.07-2.11 \text { ); } \\
\text { and hospitalization (OR } 2.35, \\
95 \% \mathrm{Cl} 1.56-3.52)\end{array}$ \\
\hline $\begin{array}{l}\text { Hass et al (65), } \\
2006\end{array}$ & $\begin{array}{l}\text { Obese: } \mathrm{BMI} \geq 25 \\
\text { Normal: } \mathrm{BMI} 18.5 \text { to } 24.9 \\
\text { Low weight: } \mathrm{BMI}<18.5\end{array}$ & $\begin{array}{l}\text { Obese }(n=48) \\
\text { Normal }(n=90) \\
\text { Low weight }(n=10)\end{array}$ & $\begin{array}{l}\text { Patient characteristics, } \\
\text { medical management of } \\
\text { symptoms and disease } \\
\text { progression }\end{array}$ & $\begin{array}{l}\text { The obese cohort was older at diagnosis } \\
\text { than the normal- and low-weight } \\
\text { cohorts ( } 35.0 \text { versus } 22.5 \text { years, } \\
\text { respectively; } \mathrm{P}=0.0001) \\
\text { Trend showed that the obese cohort had } \\
\text { a shorter time to first surgery than the } \\
\text { normal-weight cohort ( } 72 \text { versus } \\
24 \text { months, respectively; } \mathrm{P}=0.21 \text { ) }\end{array}$ \\
\hline \multicolumn{5}{|c|}{ Ulcerative colitis (UC) } \\
\hline $\begin{array}{l}\text { Efron et al (66), } \\
2001\end{array}$ & $\begin{array}{l}\text { Cases: UC }(n=27) \text {, FAP }(n=4) \\
\text { Controls: UC }(n=27), \text { FAP }(n=4) \\
\text { (disease activity not reported) }\end{array}$ & $\begin{array}{l}\text { Cases }(n=31), B M I \geq 30 \\
\text { Controls }(n=31), B M I \leq 25\end{array}$ & $\begin{array}{l}\text { Pre-, peri- and long-term } \\
\text { complications due to } \\
\text { restorative proctocolectomy, } \\
\text { blood loss during surgery, } \\
\text { continence and length of } \\
\text { hospital stay }\end{array}$ & $\begin{array}{l}\text { Cases had higher rates of pelvic sepsis } \\
\text { versus controls }(16 \% \text { versus } 0 \% \text {, } \\
\text { respectively; } P<0.05)\end{array}$ \\
\hline
\end{tabular}

BMI Body mass index $\left(\mathrm{kg} / \mathrm{m}^{2}\right)$; FAP Familial adenomatous polyposis

In general, obesity is associated with physical limitations and quality of life issues, in addition to being a causal or exacerbating agent in the course of a range of diseases. Limited scholarly information indicates that obese IBD patients also have unique risks that affect the management of disease symptoms, and their excess weight may act as a pathogenic agent. Because widespread obesity is a relatively new cultural phenomenon, future research is needed to improve patient care, disease management and weight control options.

\section{SUMMARY}

The scholarly literature provides corroborating evidence indicating that physical exercise does not affect the course of either CD or UC. As a whole, the studies conducted have several methodological limitations such as small cohort sizes and short study durations that minimize their therapeutic value. IBDs cause a range of extraintestinal manifestations that can be just as debilitating as the primary disease. Many of these conditions can also occur as primary diseases independent of bowel disease and thereby affect a greater percentage of the population. High-quality studies have been conducted to identify effective interventions for both arthritis and osteoporosis. Exercise is repeatedly found to be the most accessible, cost-effective and beneficial therapy for these diseases, and has also been associated with improvements in mental health, the immune system and weight loss.

In consideration of all the evidence collected regarding the specific benefits of exercise for IBD patients, it may be timely for the medical community to begin researching this topic in earnest. First, the effect of exercise on IBD needs to be clearly determined. If IBD is independent of exercise, then we need to determine whether there is merit in providing exercise guidelines to a patient population that has compliance difficulties due to the transitory nature of their symptoms. Likewise, because each IBD patient has a unique presentation, personalized exercise regimens are required to minimize physical risks while addressing medical limitations, disease status, medications, appliance usage and age. Developing a list of exercise suggestions from which an IBD patient may select - depending on their physical well-being at the time - may improve compliance and help to establish a routine. However, only subsequent studies will be able to convincingly determine whether any exercise is better than none at all for IBD patients.

ACKNOWLEDGEMENTS: The authors graciously acknowledge the invaluable efforts of Kathleen Ismond for researching the literature and for her extensive involvement during the construction and editing of this manuscript.

\section{REFERENCES}

1. Bernstein CN, Wajda A, Svenson LW, et al. The epidemiology of inflammatory bowel disease in Canada: A population-based study. Am J Gastroenterol 2006;101:1559-68. (Erratum in 2006;101:1945).

2. Baumgart DC, Sandborn WJ. Inflammatory bowel disease: Clinical aspects and established and evolving therapies. Lancet 2007;369:1641-57.

3. Fedorak RN, Madsen KL. Probiotics and the management of inflammatory bowel disease. Inflamm Bowel Dis 2004;10:286-99.

4. Hedin C, Whelan K, Lindsay JO. Evidence for the use of probiotics and prebiotics in inflammatory bowel disease: A review of clinical trials. Proc Nutr Soc 2007;66:307-15.

5. Ball E. Exercise guidelines for patients with inflammatory bowel disease. Gastroenterol Nurs 1998;21:108-11. 
6. Peters HP, De Vries WR, Vanberge-Henegouwen GP, Akkermans LM Potential benefits and hazards of physical activity and exercise on the gastrointestinal tract. Gut 2001;48:435-9.

7. Paffenbarger RS Jr, Hyde RT, Wing AL, Steinmetz CH. A natural history of athleticism and cardiovascular health. JAMA 1984;252:491-5.

8. Ellingson T, Conn VS. Exercise and quality of life in elderly individuals. J Gerontol Nurs 2000;26:17-25.

9. Paluska SA, Schwenk TL. Physical activity and mental health: Current concepts. Sports Med 2000;29:167-80.

10. Giovannucci E, Colditz GA, Stampfer MJ, Willett WC. Physical activity, obesity, and risk of colorectal adenoma in women (United States). Cancer Causes Control 1996;7:253-63.

11. Giovannucci E, Ascherio A, Rimm EB, Colditz GA, Stampfer MJ, Willett WC. Physical activity, obesity, and risk for colon cancer and adenoma in men. Ann Intern Med 1995;122:327-34.

12. Sanchez LD, Tracy JA, Berkoff D, Pedrosa I. Ischemic colitis in marathon runners: A case-based review. J Emerg Med 2006;30:321-6.

13. Sonnenberg A. Occupational distribution of inflammatory bowel disease among German employees. Gut 1990;31:1037-40.

14. Persson P-G, Leijonmarck CE, Bernell O, Hellers G, Ahlbom A. Risk indicators for inflammatory bowel disease. Int J Epidemiol 1993;22:268-72.

15. Boggild H, Tuchsen F, Orhede E. Occupation, employment status and chronic inflammatory bowel disease in Denmark. Int J Epidemiol 1996;25:630-7.

16. Klein I, Reif S, Farbstein H, Halak A, Gilat T. Preillness non dietary factors and habits in inflammatory bowel disease. Ital J Gastroenterol Hepatol 1998;30:247-51.

17. Cucino C, Sonnenberg A. Occupational mortality from inflammatory bowel disease in the United States 1991-1996. Am J Gastroenterol 2001;96:1101-5.

18. Marri SR, Buchman AL. The education and employment status of patients with inflammatory bowel diseases. Inflamm Bowel Dis 2005;11:171-7.

19. Halfvarson J, Jess T, Magnuson A, et al. Environmental factors in inflammatory bowel disease: A co-twin control study of a Swedish-Danish twin population. Inflamm Bowel Dis 2006;12:925-33.

20. Moeller JL. Inflammatory bowel disease arthropathy. Curr Sports Med Rep 2005;4:105-7.

21. Ireland J. Pisani out indefinitely with ulcerative colitis. Edmonton Journal (September 5, 2007). <http://www.canada.com/topics/sports/ hockey/story.html?id=1bd04e76-f593-4039-9832-d2a836787f02> (Version current at March 27, 2008).

22. Benirschke R, Yorkey M. Alive and Kicking, 2nd edn. San Diego: Rolf Benirschke Enterprises Inc, 1999.

23. Taylor R. Tight End Turnstile 1979-2003. < http://www.bearshistory.com/ lore/tightendturnstile.aspx > (Version current at March 27, 2008).

24. Elsenbruch S, Langhorst J, Popkirowa K, et al. Effects of mind-body therapy on quality of life and neuroendocrine and cellular immune functions in patients with ulcerative colitis. Psychother Psychosom 2005;74:277-87.

25. Gupta N, Khera S, Vempati RP, Sharma R, Bijlani RL. Effect of yoga based lifestyle intervention on state and trait anxiety. Indian J Physiol Pharmacol 2006;50:41-7.

26. Loudon CP, Corroll V, Butcher J, Rawsthorne P, Bernstein CN. The effects of physical exercise on patients with Crohn's disease. Am J Gastroenterol 1999;94:697-703.

27. Ng V, Millard W, Lebrun C, Howard J. Low-intensity exercise improves quality of life in patients with Crohn's disease. Clin J Sport Med 2007;17:384-8.

28. D’Inca R, Varnier M, Mestriner C, Martines D, D'Odorico A, Sturniolo GC. Effect of moderate exercise on Crohn's disease patients in remission. Ital J Gastroenterol Hepatol 1999;31:205-10.

29. O'Sullivan M, Nic Suibhne T, Shuhaibar M, O'Morain C. Lifestyle patterns in people with quiescent Crohn's disease: A role for health promotion? Digestive Disease Week 2007. Washington, May 19 to 24, 2007. (Abst)

30. Brevinge H, Berglund B, Bosaeus I, Tolli J, Nordgren S, Lundholm K. Exercise capacity in patients undergoing proctocolectomy and small bowel resection for Crohn's disease. Br J Surg 1995;82:1040-5.

31. Wiroth JB, Filippi J, Schneider SM, et al. Muscle performance in patients with Crohn's disease in clinical remission. Inflamm Bowel Dis 2005;11:296-303.
32. Izquierdo M, Ibanez J, Gorostiaga E, et al. Maximal strength and power characteristics in isometric and dynamic actions of the upper and lower extremities in middle-aged and older men. Acta Physiol Scand 1999;167:57-68.

33. Bernstein CN, Blanchard JF, Rawsthorne P, Yu N. The prevalence of extraintestinal diseases in inflammatory bowel disease: A population-based study. Am J Gastroenterol 2001;96:1116-22.

34. Dougados M, Dijkmans B, Khan M, Maksymowych W, van der Linden S, Brandt J. Conventional treatments for ankylosing spondylitis. Ann Rheum Dis 2002;61(Suppl 3):iii40-50.

35. Uhrin Z, Kuzis S, Ward MM. Exercise and changes in health status in patients with ankylosing spondylitis. Arch Intern Med 2000;160:2969-75.

36. Ince G, Sarpel T, Durgun B, Erdogan S. Effects of a multimodal exercise program for people with ankylosing spondylitis. Phys Ther 2006;86:924-35. (Erratum in 2006;86:1452).

37. Lim HJ, Moon YI, Lee MS. Effects of home-based daily exercise therapy on joint mobility, daily activity, pain, and depression in patients with ankylosing spondylitis. Rheumatol Int 2005;25:225-9.

38. Fernandez-de-Las-Penas C, Alonso-Blanco C, Alguacil-Diego IM, Miangolarra-Page JC. One-year follow-up of two exercise interventions for the management of patients with ankylosing spondylitis: A randomized controlled trial. Am J Phys Med Rehabil 2006;85:559-67.

39. Siffledeen JS, Fedorak RN, Siminoski K, et al. Bones and Crohn's: Risk factors associated with low bone mineral density in patients with Crohn's disease. Inflamm Bowel Dis 2004;10:220-8.

40. van Hogezand RA, Hamdy NA. Skeletal morbidity in inflammatory bowel disease. Scand J Gastroenterol Suppl 2006;59-64.

41. Robinson RJ. Crohn's disease, exercise and bone density. Res Clin Forums 2000;22:171-5.

42. American Gastroenterological Association. American Gastroenterological Association Medical Position Statement: Guidelines on osteoporosis in gastrointestinal diseases. Gastroenterology 2003;124:791-4.

43. Bartram SA, Peaston RT, Rawlings DJ, Walshaw D, Francis RM, Thompson NP. Mutifactorial analysis of risk factors for reduced bone mineral density in patients with Crohn's disease. World J Gastroenterol 2006;12:5680-6.

44. Gilman J, Shanahan F, Cashman KD. Altered levels of biochemical indices of bone turnover and bone-related vitamins in patients with Crohn's disease and ulcerative colitis. Aliment Pharmacol Ther 2006;23:1007-16.

45. Sylvester FA, Wyzga N, Hyams JS, et al. Natural history of bone metabolism and bone mineral density in children with inflammatory bowel disease. Inflamm Bowel Dis 2007;13:42-50.

46. von Scheven E, Gordon CM, Wypij D, Wertz M, Gallagher KT, Bachrach L. Variable deficits of bone mineral despite chronic glucocorticoid therapy in pediatric patients with inflammatory diseases: A Glaser Pediatric Research Network study. J Pediatr Endocrinol Metab 2006;19:821-30.

47. Paganelli M, Albanese $\mathrm{C}$, Borrelli $\mathrm{O}$, et al. Inflammation is the main determinant of low bone mineral density in pediatric inflammatory bowel disease. Inflamm Bowel Dis 2007;13:416-23.

48. Grey A. Emerging pharmacologic therapies for osteoporosis. Expert Opin Emerg Drugs 2007;12:493-508.

49. Henderson S, Hoffman N, Prince R. A double-blind placebo-controlled study of the effects of the bisphosphonate risedronate on bone mass in patients with inflammatory bowel disease. Am J Gastroenterol 2006;101:119-23.

50. Doggrell SA. Present and future pharmacotherapy for osteoporosis. Drugs Today (Barc) 2003;39:633-57.

51. Lee N, Radford-Smith G, Taaffe DR. Bone loss in Crohn's disease: Exercise as a potential countermeasure. Inflamm Bowel Dis 2005;11:1108-18.

52. Vainionpaa A, Korpelainen R, Leppaluoto J, Jamsa T. Effects of high-impact exercise on bone mineral density: A randomized controlled trial in premenopausal women. Osteoporos Int 2005;16:191-7.

53. Robinson RJ, Krzywicki T, Almond L, et al. Effect of a low-impact exercise program on bone mineral density in Crohn's disease: A randomized controlled trial. Gastroenterology 1998;115:36-41.

54. Rakshit RC, Almond L, al-Azzawi F, et al. Exercise and bone mineral density in Crohn's disease. Gastroenterology 2006;30:A653. (Abst) 
55. Mauro M, Armstrong D. Evaluation of densitometric bone-muscle relationships in Crohn's disease. Bone 2007;40:1610-4.

56. Minderhoud IM, Oldenburg B, Wismeijer JA, van Berge Henegouwen GP, Smout AJ. IBS-like symptoms in patients with inflammatory bowel disease in remission; relationships with quality of life and coping behavior. Dig Dis Sci 2004;49:469-74.

57. Tanaka M, Kazuma K. Ulcerative colitis: Factors affecting difficulties of life and psychological well being of patients in remission. J Clin Nurs 2005;14:65-73.

58. Bernklev T, Jahnsen J, Lygren I, Henriksen M, Vatn M, Moum B. Health-related quality of life in patients with inflammatory bowel disease measured with the short form-36: Psychometric assessment and a comparison with general population norms. Inflamm Bowel Dis 2005;11:909-18.

59. DiLorenzo TM, Bargman EP, Stucky-Ropp R, Brassington GS, Frensch PA, LaFontaine T. Long-term effects of aerobic exercise on psychological outcomes. Prev Med 1999;28:75-85.

60. Brolinson PG, Elliott D. Exercise and the immune system. Clin Sports Med 2007;26:311-9.

61. Gleeson M. Immune function in sport and exercise. J Appl Physiol 2007;103:693-9.
62. Radak Z, Chung HY, Koltai E, Taylor AW, Goto S. Exercise, oxidative stress and hormesis. Ageing Res Rev 2008;7:34-42.

63. Kugathasan S, Nebel J, Skelton JA, et al; Wisconsin Pediatric Inflammatory Bowel Disease Alliance; Pediatric Inflammatory Bowel Disease Collaborative Research Group. Body mass index in children with newly diagnosed inflammatory bowel disease: observations from two multicenter North American inception cohorts. J Pediatr 2007;151:523-7.

64. Blain A, Cattan S, Beaugerie L, Carbonnel F, Gendre JP, Cosnes J. Crohn's disease clinical course and severity in obese patients. Clin Nutr 2002;21:51-7.

65. Hass DJ, Brensinger CM, Lewis JD, Lichtenstein GR. The impact of increased body mass index on the clinical course of Crohn's disease. Clin Gastroenterol Hepatol 2006;4:482-8.

66. Efron JE, Uriburu JP, Wexner SD, et al. Restorative proctocolectomy with ileal pouch anal anastomosis in obese patients. Obes Surg 2001;11:246-51.

67. Lascano CA, Soto F, Carrodeguas L, Szomstein S, Rosenthal RJ, Wexner SD. Management of ulcerative colitis in the morbidly obese patient: Is bariatric surgery indicated? Obes Surg 2006;16:783-6. 


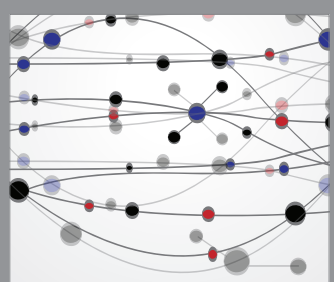

The Scientific World Journal
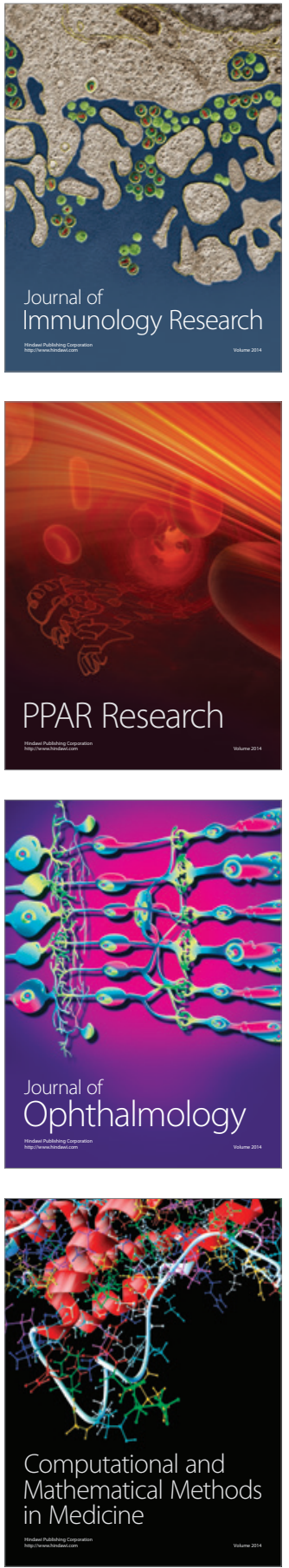

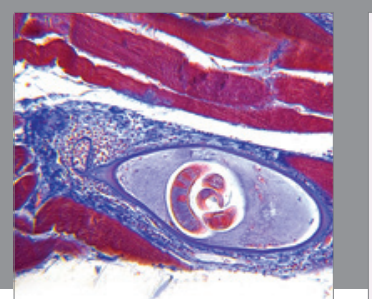

Gastroenterology Research and Practice

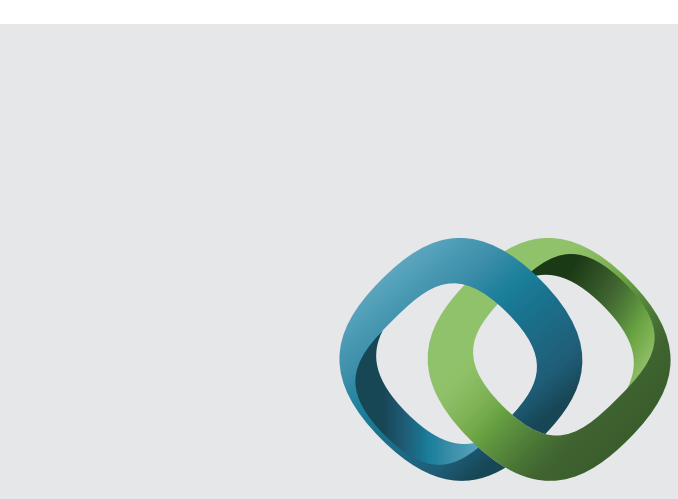

\section{Hindawi}

Submit your manuscripts at

http://www.hindawi.com
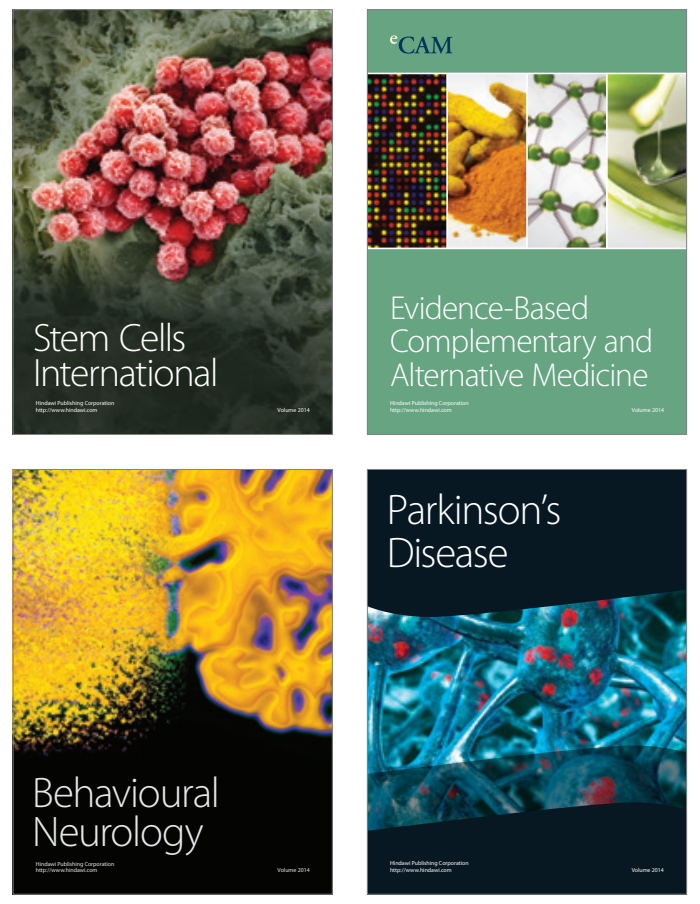
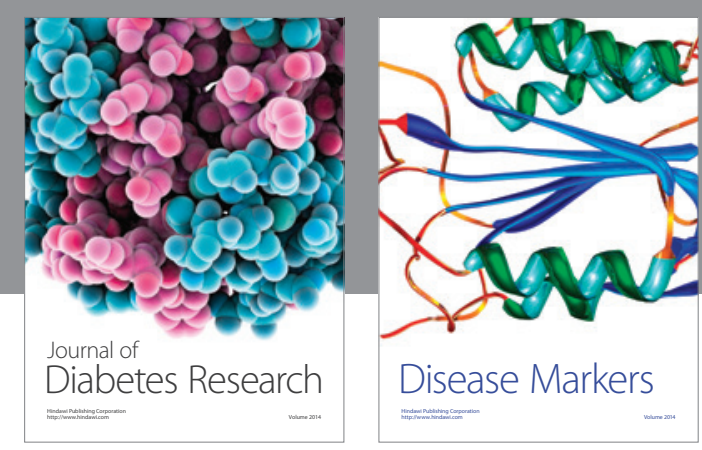

Disease Markers
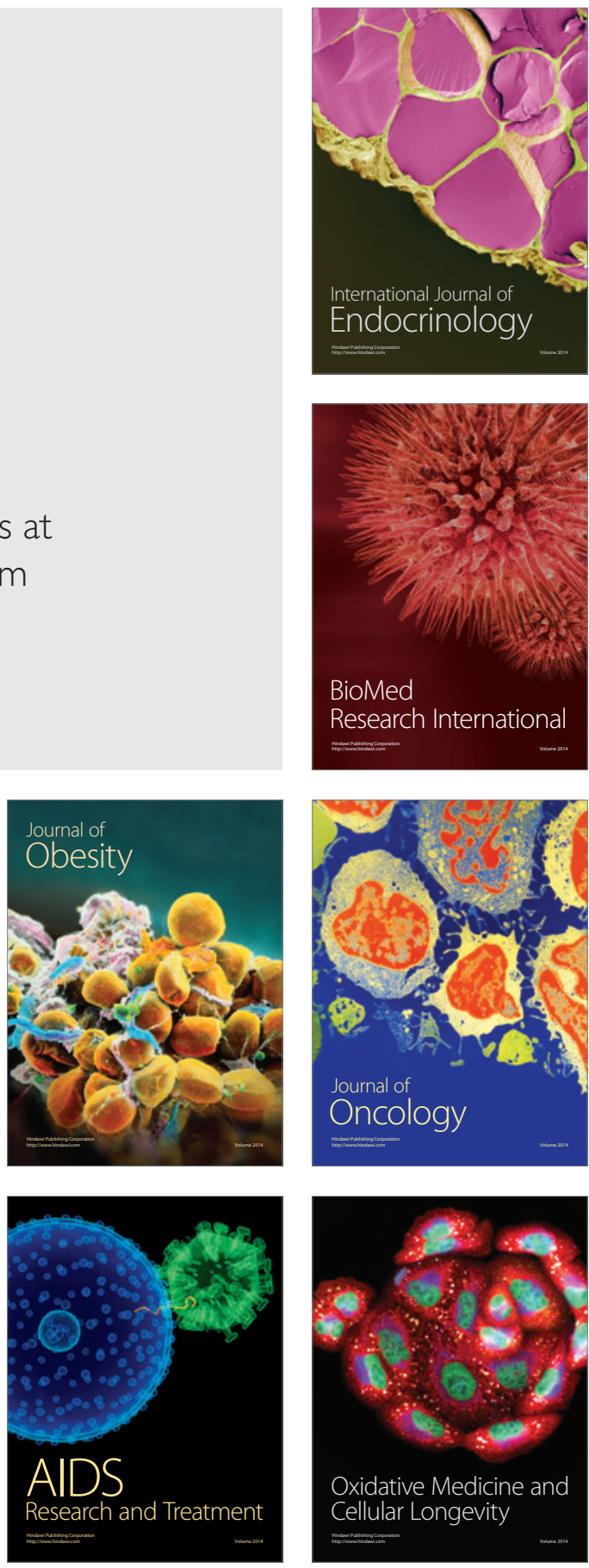